\title{
Composição em dança como crítica da imagem
}

\author{
Dance composition as image criticism
}

Larissa Ferreira ${ }^{1}$

\section{Resumo}

Este artigo apresenta uma tomada crítica sobre a elaboração da imagem em obras de dança em afecção com as tecnologias. Rejeita a abordagem que considera somente as formas da imagem, visto que não há neutralidade na composição desta. Estamos diante da complexidade dos regimes da imagem que criam danças e das danças que criam imagens e, nesta criação-afecção, produzem-se conceitos. Nesse sentido, o artigo segue desde o desejo de evidenciar o modo como a dança simultaneamente faz par com as tecnologias da imagem e esboça uma crítica a certas imagens que seguem modelos fáticos. A partir da análise de algumas cenas de Sentidos da Presença (2012), obra coreográfica da autora, evidenciam-se outras possibilidades de composição que escapam aos componentes hegemônicos da imagem contemporânea, tais como a nitidez, a velocidade e a hipervisibilidade. Discutem-se algumas táticas que foram praticadas, a saber; o desenquadramento, o fora-de-campo e a invisibilidade, como possibilidade de compor a imagem na dança como um modo de crítica da imagem.

\section{Palavras-chave}

Dança; tecnologia; imagem; composição; táticas.

\begin{abstract}
This paper presents a critical approach about the elaboration of the image in the dances in affection with the technologies. It rejects the approach that considers only the forms of the image, since there is no neutrality in this composition. We are faced with the complexity of the image regimes that create dances and dances that create images: in this creation-affection (image $\mathrm{x}$ dance) concepts are produced. In this sense This article starts with the desire to highlight the way that dance can be simultaneously engaged as a pair with the technologies of the image and to drawn a critique of certain images that follow phatic models. From the analysis of some scenes of Senses of Presence (2012) discusses other compositional possibilities that escape the hegemonic components of the contemporary image, such as sharpness, speed and hypervisibility. Some tactics that have been practiced are discussed, like; out-of-bounds and invisibility, as a possibility of composing the image in dance as a way of critical image.
\end{abstract}

\section{Keywords}

Dance; technology; image; composition; tactics.

\footnotetext{
${ }^{1}$ Professora da Licenciatura em Dança do Instituto Federal de Brasília - IFB. Mestra e Doutora em Artes - UnB. Licenciada em Dança - UFBA. Contato: larissa.ferreira@ifb.edu.br.
} 
Primeiramente, a palavra faz ver, pela narração e pela descrição, um visível não presente. Em segundo lugar, ela dá a ver o que não pertence ao visível, reforçando, atenuando ou dissimulando a expressão de uma ideia.

Rancière

A dança se compõe como pensamento e prática do corpo; parafraseando Flusser (2014), é ela mesma uma tática de vida. Daí que, neste campo de forças, este artigo pensa e reflete sobre as táticas de composição da imagem na dança. Estamos, de fato, na era das imagens (de inúmeros tipos) e o próprio corpo compõe-se como imagem, dos discursos publicitários às grandes mídias, que visam transformar os corpos em imagem fática, em imagem-atrator ${ }^{2}$. Não é novidade que o corpo na contemporaneidade seja tratado como uma espécie de corpoimagem. É esse recorrente fetichismo visual do corpo nas circunstâncias cotidianas que corrobora a pautar a urgência do debate sobre as tecnologias da imagem na dança. Então, é preciso indagar: quais corpos e|ou quais imagens? Ou que corpo-imagem determinada obra coreográfica produz? Um corpo de conceitos, práticas e danças; que toma o corpo e, logo, a dança, no território das problematizações.

Sendo assim, com o intuito de problematizar o campo destas relações (corpo X imagem), serão tomadas algumas cenas de Sentidos da Presença - 2012 (obra da autora). No contexto da composição da imagem como afecção do corpo que dança, o corpo em cena deixa-se afetar e a imagem projetada corta a pele como uma lâmina com aparência de luz. Desde uma tomada crítica de percepção e elaboração da imagem na dança, não limitamo-nos a considerar somente as formas da imagem, visto que não há neutralidade na imagem. Estamos diante da complexidade destas lâminas e camadas que compõe os regimes da imagem que

${ }^{2} \mathrm{O}$ "atrator" é um conceito chave do fetichismo: "O atrator anula temporariamente o movimento do olho exercendo um poder que une o olhar e a coisa que determina os novos cursos dos fetichismos visuais difundidos da metrópole comunicacional" (Canevacci, 2008: 16). Nesse sentido, o corpo não é apenas corporal, mas expande-se em edifícios, coisas-objetos-mercadorias e imagens, numa coisificação do corpo (Canevacci, 2008:18). 
criam danças, mas também produzem conceitos. A dança faz par com as tecnologias da imagem, contudo, não deixa de esboçar uma crítica a certas imagens que seguem modelos fáticos ${ }^{3}$. Com o intuito de discutir como se dão as parcerias e ções, passaremos a algumas cenas de Sentidos da Presença e seu processo de composição, notadamente com o interesse em perceber as lógicas de composição da imagem. Decifrar as lâminas de luz.

\section{Sobre a obra Sentidos da Presença}

A obra Sentidos da Presença (Ferreira, 2012) parte do conceito de presença para refletir sobre o corpo na contemporaneidade, constantemente em afecção com as tecnologias. Vivemos na era das realizações e inventos tecnológicos, onde o sujeito tem a sua presença mediada por estes dispositivos. Questiona-se: Qual a presença do corpo na imagem? Investigam-se os modos de presença do corpo, expandidos pela tecnologia. Mas, também os modos de presença em contração, minimizados por dispositivos que podem, por exemplo, diminuir ou silenciar o som produzido pelo corpo, seja a sua respiração ou os batimentos cardíacos. Assim, o ponto de partida para a obra é o jogo entre a oscilação dos graus de presença do corpo, seu movimento e sua imagem.

As cenas foram compostas como uma possível tática que pudesse contemplar as questões sobre a presença. Inicialmente, a discussão sobre o conceito de presença foi experimentada a partir da relação entre visibilidade e invisibilidade. No processo de construção das cenas surgiram alguns tópicos intrigantes: Como perceber o que não vejo? Desde a perspectiva da cultura visual e sua hipervisão instaurada, muitas das cenas foram compostas desde a possibilidade de perceber outros modos de acesso à relação entre dança e tecnologias da imagem. De evi-

\footnotetext{
${ }^{3}$ A imagem-fetiche relaciona-se com a "imagem fática", um termo de Georges Roques (em Essai sur Magritte et la Publicité) utilizado por Paul Virilio (Virilio, 1994: 32). A imagem fática definese como imagem-alvo que força o olhar e prende a atenção, sobretudo em propagandas e anúncios que compõem a indústria da visão. Virilio chama a atenção para a produção de imagem fática no campo da publicidade, onde esta tem se colocado mais como clichê do que como imagem potente: "A imagem fática que se impõe à atenção e obriga o olhar não é mais uma imagem potente, mas sim um clichê" (Virilio, 1993: 130).
} 
denciar outras possibilidades de abordagem e composição, que escapam à nitidez, à velocidade e à hipervisibilidade das imagens contemporâneas, uma vez que as imagens digitais contemporâneas frequentemente realizam-se a partir destes três componentes hegemônicos. No campo da imagem, tal eficiência está ligada ao nítido, o veloz, o hipervisível, dentre outros. Nesse sentido, a obra Sentidos da Presença busca reinventar e dessacralizar a imagem a partir de outros parâmetros poéticos. Nessa lógica de composição, praticou-se o recorte, o desenquadramento, o fora-de-campo e a invisibilidade, como possibilidade de compor ${ }^{4}$ a imagem na dança como um modo de crítica da imagem. Se a imagem compõe-se notadamente pela evidente visibilidade, instigar a invisibilidade talvez possa incorporar à dança o aspecto reivindicado da crítica à imagem e seus modos fáticos da hipervisão.

\section{Decupagens em corpo: as operações de desenquadramento e o fora-de-campo}

Em várias cenas constitui-se o que chamo de "corpo editado", cujas imagens projetadas são formas geométricas, em branco, cinza escuro, vermelho, um quadrado, um retângulo, linha vertical, linha horizontal. A imagem-luz faz uma “edição do corpo", uma espécie de corte seco nas superfícies porosas da pele (ver figura 3 e 4). Os recortes e decupagens agenciadas pela imagem-luz corroboram para uma espécie de visibilidade editada do corpo. Dança-se um jogo de (in) visibilidades agenciadas a partir dos recortes, da imagem-luz que ilumina ou nega a vidência. Estas imagens, em Sentidos da Presença, compõem o jogo entre os quadros e os múltiplos recortes do corpo. Faixas de imagem-luz contrastam com o que não se dá a ver no escuro. Como bem coloca Raymond Bellour (2007), tais cortes inscrevem fisicamente a relação entre visibilidade e invisibilidade operada sobre a presença do corpo, num jogo entre (não) ver e ver:

Isso se traduz em primeiro lugar no trabalho do enquadramento

\footnotetext{
${ }^{4}$ Embora sejam muitas as táticas de composição da imagem praticadas sem Sentidos da Presença, nos ateremos principalmente às cenas que compõe a relação corpo $\mathrm{x}$ imagem a partir das três táticas de composição já citadas: desenquadramento, fora-de-campo e invisibilidade, modos que cruzam não somente o campo do cinema, mas também o espaço da dança.
} 
(multiplicados pelo jogo entre os quadros, as múltiplas telas, e a faixa preta que contorna a imagem): os cortes sempre se dão nos corpos de forma a inscrever fisicamente a presença-relação da falta e do incognoscível, a relação entre (não) ver e (não) saber (Bellour, 2007: 211).

Ao ler Bellour, fica nítida a sensação de que a obra deseja ir além dos esquemas perceptivos que privilegiam a visão. Ao contrário, clama pelo engajamento corporal. Os múltiplos jogos entre o que se dá a ver e não, o que se esconde e se mostra, incita a percepção do público que instigado pelo sentido da visualidade, é encorajado à cinestesia, à corporalidade. Diante da corporalidade engajada nos modos perceptivos de recepção em Sentidos da Presença, surge o olhar incorporado, conceito e prática criada durante a obra citada e depois aprofundado em Corpo em Obra (2013), obra também concebida pela autora.

No que tange ao olhar incorporado, não se trata de um privilégio do olhar, mas antes volta-se para a negação do automatismo do olhar, e, logo, nega o automatismo sensório. O olhar incorporado enfatiza a totalidade do corpo, uma espécie de imago-gestus. Está ligado à imagem que não ser quer deixar automatizar, e ao agenciamento dos modos de ver e ser visto, implicados nos regimes da imagem. O olhar incorporado é corpo e sensação naquilo que se vê. Afasta-se da disciplina técnica "visiônica" que obtém a visão sem o olhar (Virilio, 1994: 46). Pactua-se com o háptico e se afasta do fático: "Háptico é um termo melhor do que tátil, pois não opõe dois órgãos dos sentidos, porém deixa supor que o próprio olho pode ter essa função que não é óptica. [...] Pode ser visual, auditivo, tanto quanto tátil” (Deleuze e Guattari, 2007: 203). Nesse sentido, o olhar incorporado envolve uma desprogramação do automatismo do olhar (público|audiência) que é convidado a perceber as minucias do que não se vê. $O$ sentido da imagem vai além da aparência (Flusser, 2008: 65). Importam as tessituras|relações que nem sempre são visíveis. De modo que a invisibilidade mostra ao que a imagem se propõe, ou ao que se propõe a dança. De outro modo, a dança faz par com as tecnologias da imagem, mas não deixa de esboçar uma crítica a certas imagens que seguem modelos fáticos. Assim, não se trata de "o quê", mas sim do "como" estas relações estabelecem-se, como se dão as parcerias. 
VIS

Revista do Programa de Pós-graduação em Arte da UnB

Interessada nos Sentidos da Presença que podem ser agenciados pela presença das tecnologias da imagem, esse constante jogo entre visibilidade e invisibilidade na obra, ultrapassa o conceito de presença como "aquilo que se dá a ver". Direciona o caminho de volta ao perceptivo, engajamento do corpo: sensação, corporalidade e cinestesia. Há que estar atento para perceber onde está o corpo, para onde se move e dança. A presença se espalha.
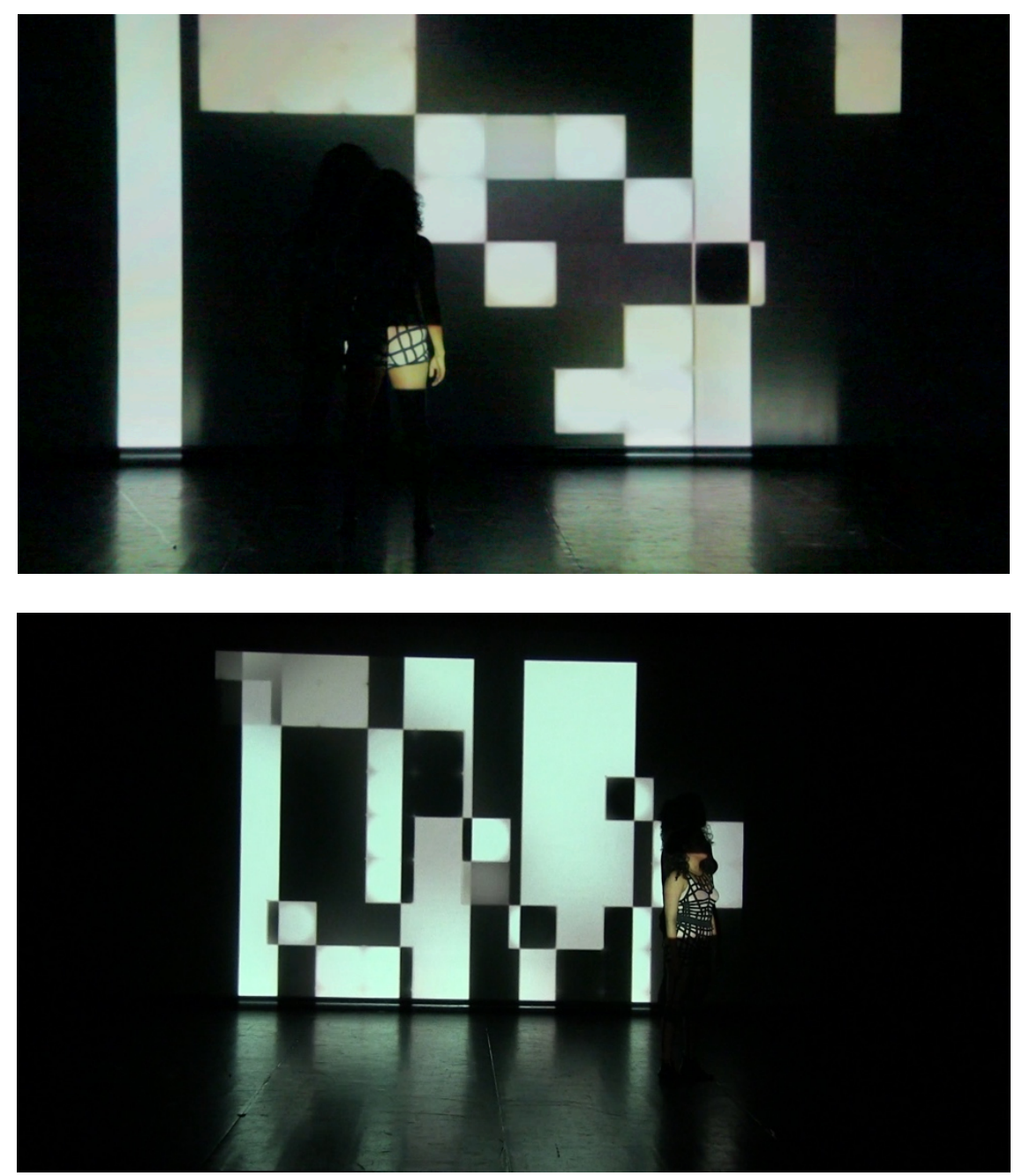
VIS

Revista do Programa de Pós-graduação em Arte da UnB
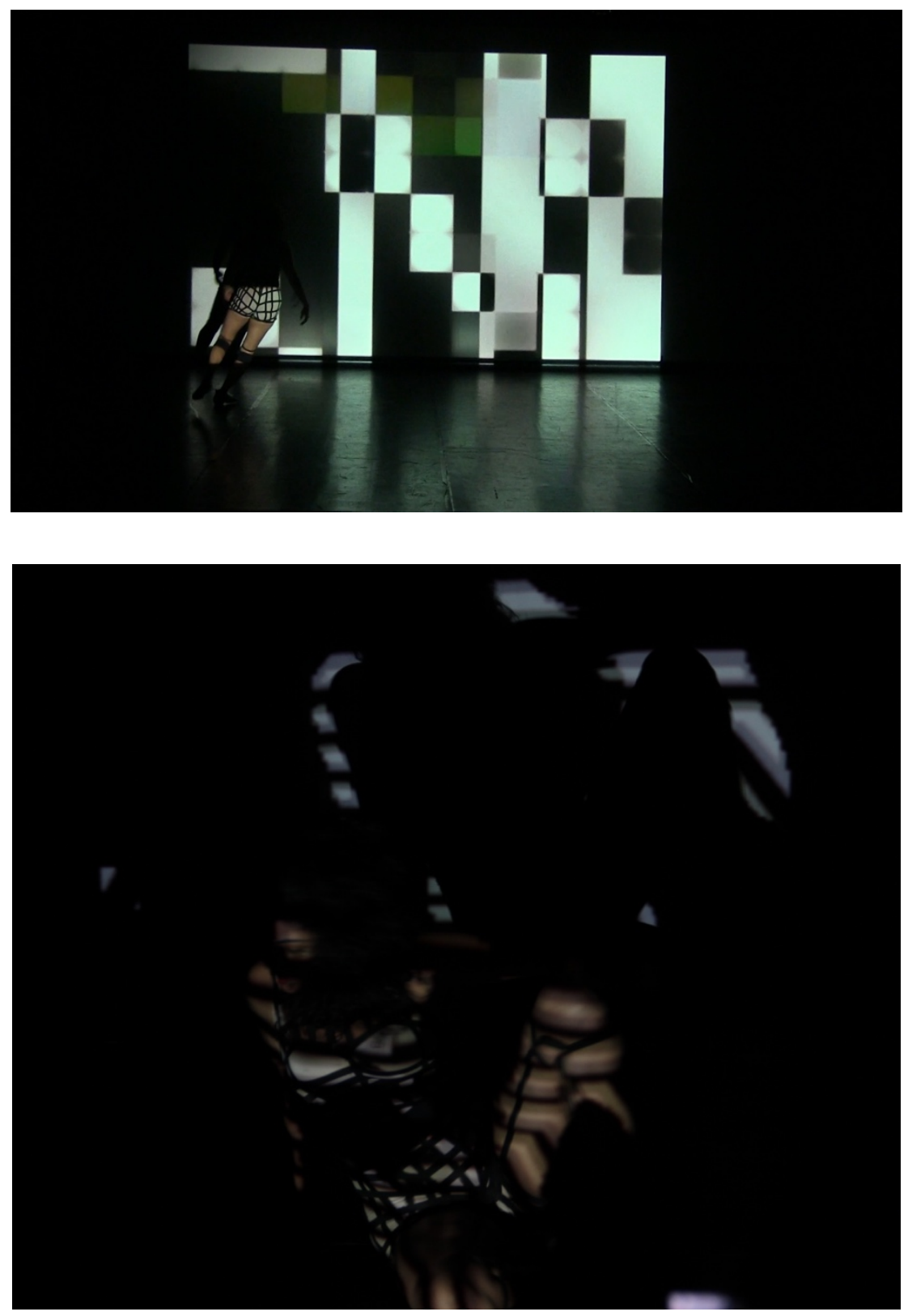

Figuras1, 2, 3 e 4. Larissa Ferreira, Sentidos da Presença, 2012.

\section{Fora-de-campo: praticando os deslimites}

Ao discutir o (des)enquadramento, vem à tona as reflexões sobre as bordas e o fora-de-campo. As bordas têm o duplo papel de separar a imagem do seu exterior. Sobre as bordas: "Também o que faz comunicar o interior da imagem, o que em cinema chamamos de campo, com seu prolongamento imaginário, o fora-decampo" (Aumont, 2011: 86). Caso explique-se um conceito da imagem com outra 
imagem, o fora-de-campo está implícito na metalinguagem operada por Edgar Degas, nos espelhos que deixam ver o que se esconde fora das bordas do quadro.

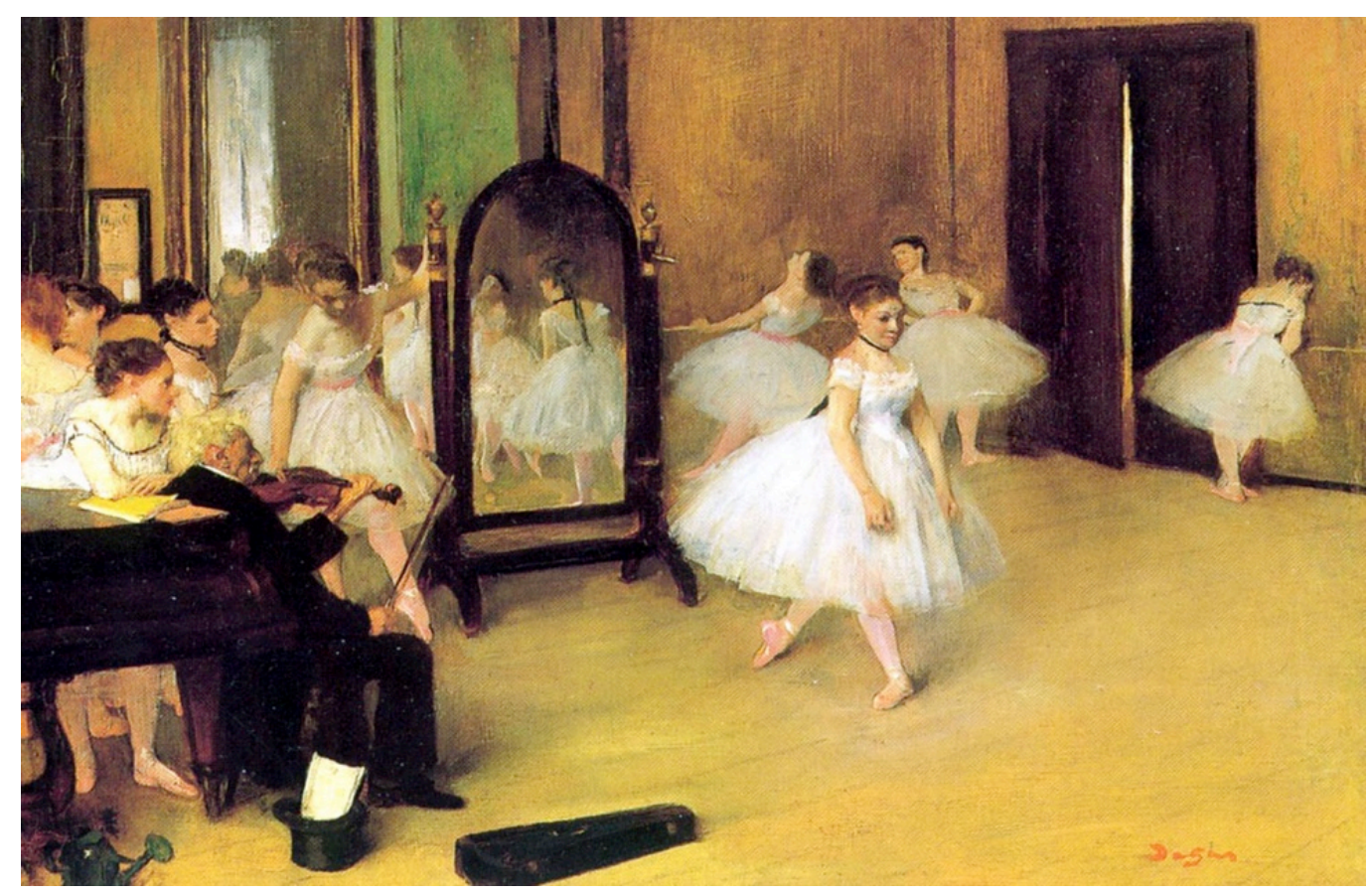

Figura 5. Edgar Degas, The Dancing Class, c. 1871-1872.

Já no palco cênico, não há moldura que separe as presenças da imagem e a presença do corpo. Visto que, nas danças em afecção com as tecnologias, frequentemente as imagens projetam-se na cena como se fossem camadas do próprio palco. Como nas telas que se colocam na diagonal fundo do palco. E, quase sempre, as imagens projetadas ocupam todo o square da tela. A quarta parede é a borda simbólica das danças que se realizam em palcos cênicos. Em Sentidos da Presen$c ̧ a$, os recortes da imagem projetada agenciam pequenos cortes nesse grande espaço, compõe as bordas imaginárias entre corpo e imagem nos limites entre o invisível e o visível dos cortes da imagem e do corpo. O que se mostra e o que se esconde como fora. Aumont faz uma observação sobre o fora-de-campo e o fetiche. Coloca este último como o lugar para o qual o olhar se desvia, como se caminhasse para o proibido, o que não se pode ver. "Essa relação entre campo e fora-decampo evoca outra relação, entre o lugar, para onde todo o olhar se vê negado, da castração, e o lugar mesmo ao lado, que é o do fetiche (Aumont, 2011: 61). Para 
isso, o autor retoma os conceitos da castração em Freud, que não levaremos adiante, já que este escrito não vai aprofundar questões da psicanálise enquanto referência básica da pesquisa.

Ao pensar no sentido literal do quadro e enquadramento, a obra Square Dance (Bruce Nauman, 1967-68) vem à tona. Uma obra que se compõe a partir do enquadramento, faz uma crítica ao sistema hegemônico formal do grid (telaquadro) nas artes visuais. Do mesmo modo, essa passagem de Gilles Deleuze, sobre a obra Quad de Samuel Beckett, poderia referir-se também às noções de enquadramento em Dance Square:

É um espaço qualquer fechado, globalmente definido [...]. Cada um parte de um vértice de um ponto cardial, qualquer personagem recorre ao quadrado, cada um seguindo um curso com direções dadas [...]. Não são afetados eles mesmos por nada mais que sua ordem e sua posição. São personagens desafectados em um espaço desafectado [...]. Os personagens acontecem e se cansam nas quatro esquinas do quadrado, sobre os lados e as diagonais. Mas, realizam e esgotam o centro do quadrado, ali onde as diagonais se cruzam (Deleuze, 2010: 87-88 ).

Embora a performance de Nauman não finalize no meio do quadrado, esta forma geométrica constrói-se como um espaço que delimita o movimento do performer que percorre as bordas do quadrado e deixa o centro vazio. Como afirma Deleuze, o quadrado como um espaço que não se afeta, e o corpo que, contido neste espaço, também não se afeta. Nesta obra, trata-se de percorrer linearmente as linhas do quadrado como um movimento mecânico e automático. E, nesse sentido, a delimitação pode relacionar-se diretamente às ações de controle sobre o espaço e o corpo. E, se o enquadramento pode ser tomado como uma operação de controle do espaço, interessam, então, as possibilidades do desenquadramento. 
VIS

Revista do Programa de Pós-graduação em Arte da UnB

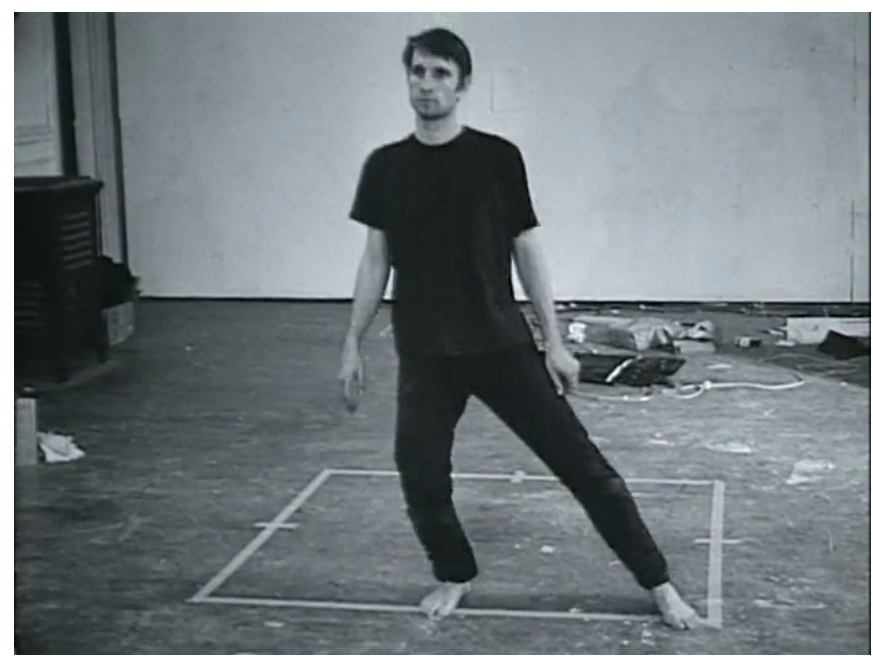

Figura 6. Bruce Nauman, Dance or Exercise on the Perimeter Square (Square Dance), 1967-68.

\section{Desenquadramento como tática de composição em dança}

O desenquadramento, como uma possível tática de composição na dança, foi muitas vezes utilizado por Merce Cunningham em sua proposta de desierarquização do espaço cênico na dança, que rejeita o tal "estilo clássico como essencialmente centrado" (Aumont, 2011: 154). Para o coreógrafo, nenhum ponto é mais importante que o outro:

A ideia de foco único ao qual tudo adere já não é mais relevante. Com as pinturas de Jackson Pollock os olhos podem ir a qualquer parte da tela. Nenhum ponto é mais importante que outro. Nenhum ponto leva necessariamente a outro (Cunningham, 2014: 138).

O sentido de desenquadramento também sucede quando proposições de dança saem das caixas do teatro e realizam-se no espaço da cidade. Cunningham realiza os Eventos (events), no qual rompe com a ideia do teatro como único espaço possível para a dança, apresenta-se em museu, foyer, ginásios esportivos, praças, dentre outros espaços. Sobre os Events: “À medida que nos apresentávamos nessas diferentes situações, tornou-se primordial que as obras fossem criadas para caber num local específico, e sim que se olhasse para cada nova situação e visse como lidar com ela" (Cunningham, 2014: 176). Sobre o enquadramento no contexto da imagem em movimento: 
Enquadramento desviado, acentuado enquanto tal e que pretende afastar o enquadramento da equivalência automática do olhar. O desenquadramento esvazia o centro da imagem e introduz uma tensão visual, dada a tendência do espectador para querer reocupar o centro vazio. Deslocando as zonas significantes (em geral as personagens) para longe do centro, ele acentua suas bordas da imagem, e o lado visivelmente deliberado dessa acentuação sublinha o fato de essas bordas serem o que separa a imagem do fora-de-quadro (Aumont, 2011: 93).

Ao traçar uma relação com Cunningham, o sentido do preenchimento do espaço não se completa, visto que o coreógrafo trabalha com outra lógica de espaço. Lógica esta que combate os automatismos do olhar e da percepção espacial. Embora Sentidos da Presença ocupe o espaço do teatro, há táticas de desenquadramento como composição, incitada pelos atravessamentos entre o fora-decampo e a invisibilidade.

O enquadramento é limitação. Mas, de acordo com o próprio conceito, os limites podem ser concebidos de dois modos, matemático ou dinâmico: ou como condições para a existência dos corpos cuja essência os limites vão fixar, ou como algo que se estende precisamente até onde vai a potência do corpo existente (Deleuze, 1986: 23-24).

Deleuze, ao definir o enquadramento, reflete sobre o quadro a ser rompido pelo corpo que, com sua potência, rejeita os limites. O fora-de-campo composto nas cenas|danças da obra Sentidos da Presença, sucede na rejeição dinâmica aos limites. É incitado pelo desenquadramento, neste caso, de um corpo que não cabe dentro do quadro (da projeção-luz), ao contrário escapa pelas bordas, pelas fissuras da imagem-luz. As imagens recortam o corpo, desde o princípio. O “espectador" deseja ver, mas a totalidade não é revelada. Estes modos de desenquadramento e fora-da-imagem compostos em Sentidos da Presença estão em várias cenas que se compõe recortando o corpo com uma lâmina luz, da projeção que é luz mapeada em formatos geométricos, já citados anteriormente. A luz projetada como um modo de editar o corpo, delimitando uma espécie de fora-de-campo como um fora da luz, considerando que o fora-de-campo em Sentidos da Presença é o que quase não se dá a ver, o que se constitui na relação entre o que a imagem esconde ou revela. Em uma dessas cenas (figura 8, 9, 10 e 11), o corpo oscila a 
VIS

Revista do Programa de Pós-graduação em Arte da UnB

um lado e outro e nesta oscilação os graus de (in)visibilidade vão mudando. $\mathrm{Na}$ última oscilação a um dos lados, em movimento contido que vai lentamente levando o seu peso, parece que se anuncia uma queda no escuro, já que há um blackout. O que pode ser afirmado diante dessa tal invisibilidade, da imagem que edita o corpo como se estivesse fazendo cortes secos no próprio movimento ? A ambiguidade anuncia-se. Há um embate entre aquele que quer ver o breu e o que esconde a suposta queda. O fora-de-campo então se coloca como algo potente na composição desta cena. Assim, como um punctum (Barthes, 2015) que incita o desejo de atravessar a imagem e perceber o que se esconde ao lado da foto, o que não se dá a ver.
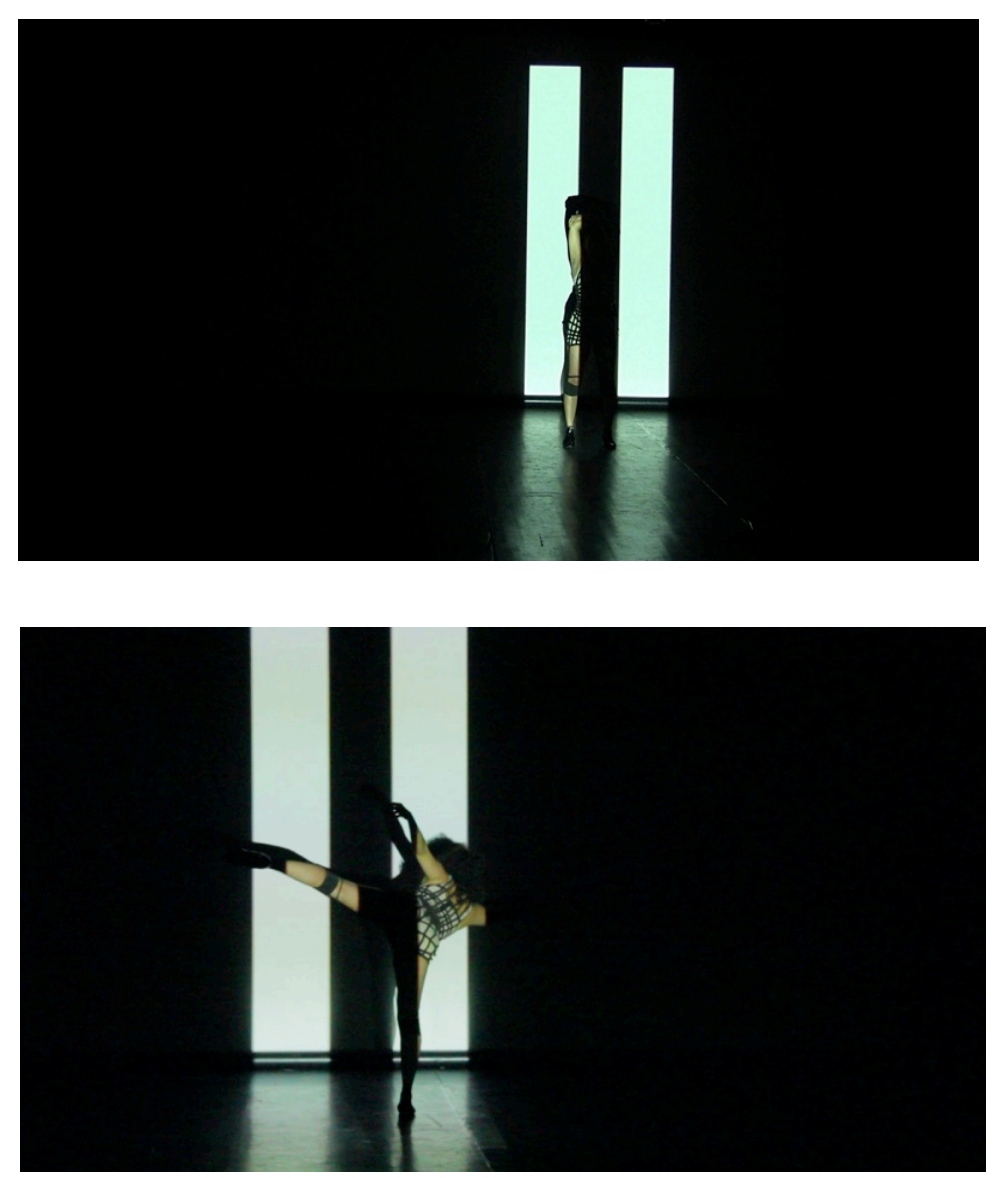
VIS

Revista do Programa de Pós-graduação em Arte da UnB
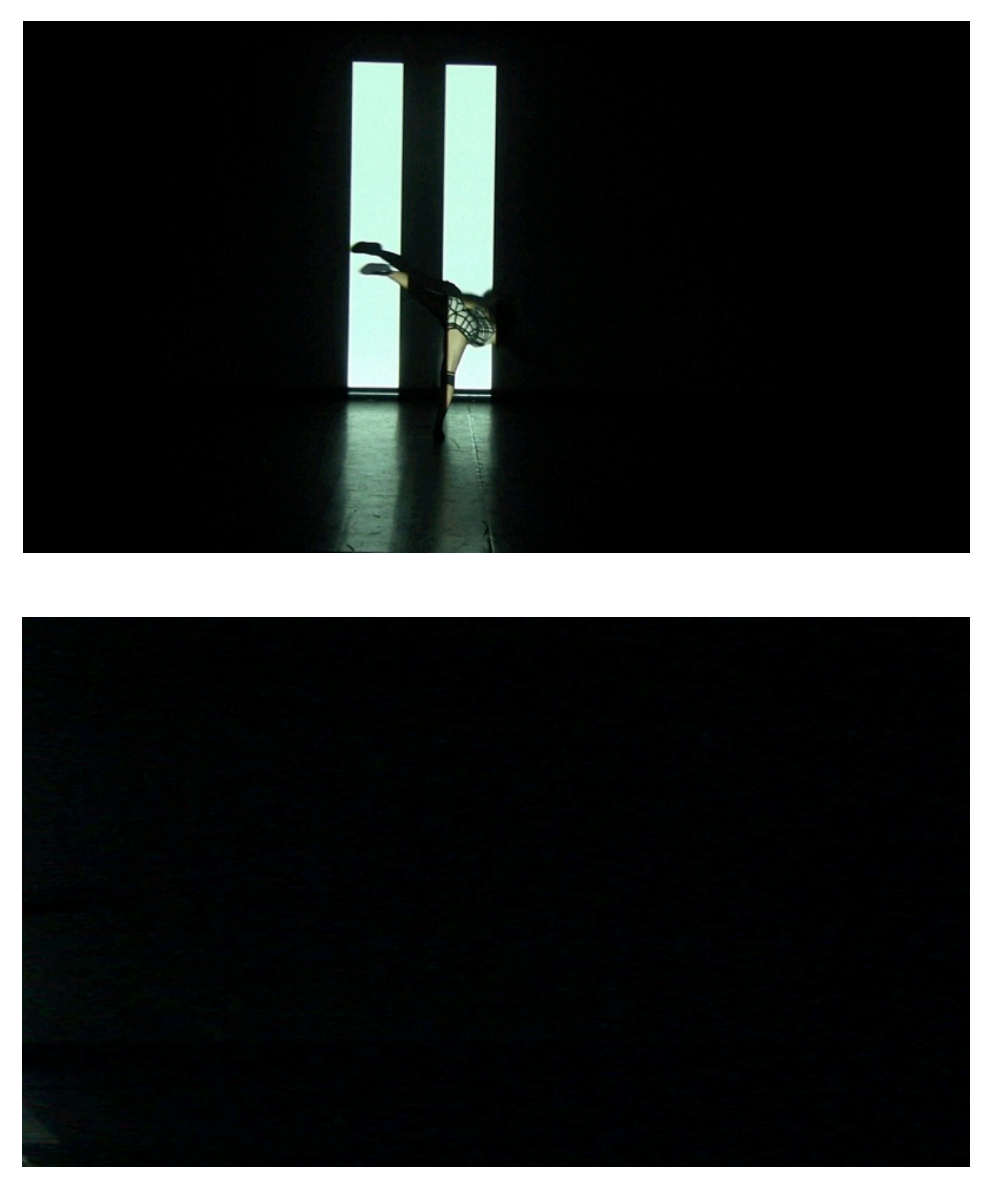

Figuras 7, 8, 9 e 10. Larissa Ferreira, Sentidos da Presença, Brasília, 2012.

\section{Tendências em movimento: composição da dança como crítica da imagem}

Considerando que a escrita do artigo moveu-se pelo desejo de evidenciar táticas e possibilidade de composição da imagem na dança como um modo de crítica da imagem, vale aproximar-se de Philippe Dubois na tentativa de compreender quais as linhas de força implícitas nessa dança-escrita. Dubois enumera algumas lógicas de composição da imagem, dentre as quais estão: lógica do grid (quadro), do panóptico, de espelhamento, dentre outras. A questão do enquadramento atravessa a três lógicas de composição. Atravessa o grid, no sentido que coloca-se dentro ou fora da grade, mas também a lógica da imagem panóptica, do espaço geometricamente esquadrinhado, da geometrização do espaço. Tomando o breve contágio com estas três lógicas, qual a potência implícita no fora-de-campo, por qual razão envolvê-lo na composição da obra e na discussão? Poderia também 
reescrever a questão substituindo o fora-de-campo pelo agenciamento de invisibilidades e|ou o elogio ao desenquadramento. Dito isto, qual a implicância destas táticas de composição (invisibilidades, desenquandramento e fora-de-campo) para instaurar uma composição crítica da imagem? Não é pelo olhar que se desvia, mas pela busca da invisibilidade e da desconstrução do próprio grid da imagem panóptica. Se o panóptico (Foucault, 1997) está ligado ao sistema de vigilância e o olhar (quase anônimo) daquele que faz a vigília, as táticas citadas agenciam um modo hipersensorial do ver. O olhar incorporado novamente faz refletir sobre o desvio da especulação. Uma postura crítica a fim de propor uma estética mais ressonante, longe do imperativo fotológico. Agencia-se também um desvio das funções do dispositivo, que quer mostrar a imagem. A imagem ainda mostra; as nuances entre claro e escuro, entre luz e escuridão, um corte do corpo em frestas na qual talvez se possa perceber que a dançarina está presente no palco. Contudo, compõe-se uma imagem que pede ao público que se mova da cadeira, que experimente diferentes perspectivas e miradas, no sentido de constatar se o corpo permanece no palco ou até onde se esconde nas frestas pouco iluminadas. A imagem-alvo se dissolve no breu, nos cortes e no turvo. Afasta-se da hipersivibilidade. O público é instigado a tatear ao invés de ver. Tocar ainda que seja com o tato dos olhos: "a visão toca e o tato vê" (Serres, 2005: 29). Voltamo-nos para o corpo. O olhar incorporado é evocado, entre o ver e o não ver; incita uma mirada para o invisível e agencia uma percepção da presença que vai além do visível. O movimento que se oculta no breu e a dança entre as lâminas de luz que cortam o corpo.

\section{Referências}

AUMONT, Jacques. A imagem. Trad. Estela dos Santos Abreu e Cláudio Cesar

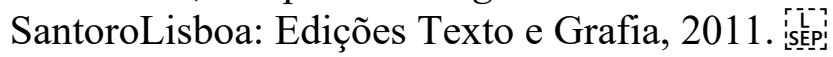

BARTHES, Roland. A câmara clara. Trad. Julio Castanon Guimarães. Editora Nova Fronteira: Rio de Janeiro, 2015.

BELLOUR, Raymond. Entre-Imagens. Trad. Luciana A. Penna. São Paulo: Papirus, 2007.

CANEVACCI, Massimo. Fetichismos Visuais: Corpos Erópticos e Metrópole Comunicacional. São Paulo, Ateliê editorial, 2008. 
CUNNINGHAM, Merce. $O$ dançarino e a dança: conversas com Jacqueline Lesschaeve. Trad. de Julia Sobral Campos. Rio de Janeiro: Editora Cobogó: 2014.

DELEUZE, Gilles. Sobre o Teatro: Um manifesto de menos I O esgotado. Rio de Janeiro: Zahar, 2010.

tora $34,1986$. . Imagem-Movimento. Trad. Stella Senra. Rio de Janeiro: Edi-

DELEUZE, Gilles e GUATTARI, Félix. Mil Platôs. vol. 5. Trad. Peter Pál Pelbart e Janice Caiafa. Rio de Janeiro: Ed. 34, 2007.

FLUSSER, Vilém. O universo das imagens técnicas: Elogio da Superficialidade. São Paulo: Annablume, 2008. . Gestos. São Paulo: Annablume, 2014.

FOUCAULT, Michel. Michel. Vigiar e Punir. Trad. Raquel Ramalhete. Petrópolis: Editora Vozes, 1997.

RANCIÈRE, Jacques. O destino das imagens. Trad. Monica Costa Netto. Rio de Janeiro: Contratempo, 2012.

SERRES, Michel. Variações sobre o corpo. Trad. de Edgard de Assis Carvalho; Mariza Perassi Bosco. São Paulo: Bertrand Brasil, 2005.

SPINOZA, Benedictus de. Ética. Trad. Tomaz Tadeu. São Paulo: Autêntica, 2008.

VIRILIO. Paul. A máquina de visão. Trad. Paulo Roberto Pires. São Paulo: José Olympio, 1994.

. A imagem virtual, mental e instrumental. Trad. Carlos Irineu da Costa. In: PARENTE, André (Org.) Imagem-máquina: A era das tecnologias do virtual. Rio de Janeiro: Ed. 34, 1993. 